\title{
Time Course of Effect of Disodium Cromoglycate on Exercise-induced Asthma
}

\author{
M. SILVERMAN and TINA ANDREA \\ From the Department of Paediatrics, Institute of Diseases of the Chest, London
}

\begin{abstract}
Silverman, M., and Andrea, T. (1972). Archives of Disease in Childhood, 47, 419. Time course of effect of disodium cromoglycate on exercise-induced asthma. Exercise tests, consisting of 6 minutes of continuous running, were performed on 10 asthmatic children known to develop exercise-induced bronchoconstriction. Disodium cromoglycate was equally effective in preventing postexercise bronchoconstriction, whether given 20 minutes before or immediately before exercise. There was a small but significant effect when it was administered at the end of exercise. No placebo effect was noted. Bronchodilatation which occurred during exercise appeared to be enhanced when the drug was given immediately before exercise, but the maximum values of peak expiratory flow rate achieved during exercise were similar in all tests.

In practice, no delay is therefore required between administration of disodium cromoglycate and the start of exercise, and the drug can be used in situations that might previously have demanded the use of bronchodilator aerosols for immediate effect.
\end{abstract}

Exercise-induced bronchoconstriction (EIB) is a common feature of childhood asthma (Jones, Buston, and Wharton, 1962) and an increasingly recognized symptom of asthma in adults. The efficacy of disodium cromoglycate (DSCG) in diminishing the effect of exercise in those patients who have the symptom has been shown in children (Blackhall and Jones, 1970; Connolly and Godfrey, 1970) and in adult patients (Davies, 1968). DSCG is also effective in diminishing the immediate reaction to bronchial challenge testing with inhaled allergens and is effective when given 10 minutes before the inhalation (Pepys et al., 1968).

Only one study in which an attempt has been made to determine the minimum effective interval between the administration of DSCG and the start of exercise in patients with EIB (Blackhall and Jones, 1970) has been done. Only one patient was studied and the results did not conform with our own personal observations. No report has been found of the effect of DSCG given after exercise. This study was designed to obtain information about the time course of action of DSCG by means of simple exercise tests in children.

Received 15 November 1971.

\section{Patients and Methods}

The 10 children, aged between 8 and 15 years, were attending the Brompton Hospital Paediatric Chest Clinic. They all had asthma, according to the definition of Scadding (1969), and were selected for this study solely on the grounds that they developed EIB, i.e. a fall in peak expiratory flow rate (PEFR) of more than $15 \%$ after exercise. Details of patients' anthropometry, current drug therapy, and the summarized results of prick testing with a range of 22 common antigens are given in Table $I$.

For each patient, no more than one test was performed on any day. No patient had taken DSCG or bronchodilators within 10 hours or antihistamines within 24 hours of any test. Spirometry was performed before each exercise test and tests were only carried out in any patient if the results were similar to those obtained before previous tests in the series.

Each patient carried out one form of running test, either on a treadmill (Quinton) set at speed and slope sufficient to produce a heart rate of more than 160 beats $/ \mathrm{min}$, or in a long corridor. The duration of exercise was 6 minutes, PEFR being measured every 2 minutes during running. Those children who ran in the corridor had to stop briefly during exercise in order to perform the PEFR manoeuvres. Heart rate was measured at the end of exercise either by means of an ECG-triggered heart rate monitor or by counting the pulse rate at the wrist. PEFR was measured after 
TABLE I

Anthropometric and Clinical Data

\begin{tabular}{|c|c|c|c|c|c|c|}
\hline Case No. & Sex & $\begin{array}{l}\text { Age } \\
(\mathrm{yr})\end{array}$ & $\begin{array}{l}\text { Height } \\
\text { (cm) }\end{array}$ & $\begin{array}{l}\text { Weight } \\
\text { (kg) }\end{array}$ & $\begin{array}{l}\text { Current Drug } \\
\text { Treatment }\end{array}$ & $\begin{array}{c}\text { Number of Positive } \\
\text { Prick Tests }\end{array}$ \\
\hline $\begin{array}{r}1 \\
2 \\
3 \\
4 \\
5 \\
6 \\
7 \\
8 \\
9 \\
10\end{array}$ & $\begin{array}{l}\text { F } \\
\mathbf{M} \\
\mathbf{F} \\
\mathbf{M} \\
\mathbf{M} \\
\mathbf{F} \\
\mathbf{M} \\
\mathbf{F} \\
\mathbf{M} \\
\mathbf{F}\end{array}$ & $\begin{array}{r}12 \\
9 \\
8 \\
7 \\
15 \\
9 \\
11 \\
9 \\
9 \\
13\end{array}$ & $\begin{array}{l}153 \\
130 \\
132 \\
116 \\
163 \\
137 \cdot 5 \\
136 \cdot 5 \\
126 \\
130 \\
144\end{array}$ & $\begin{array}{l}42 \\
27 \cdot 5 \\
25 \\
22 \cdot 4 \\
60 \cdot 9 \\
32 \cdot 2 \\
33 \cdot 6 \\
24 \\
23 \cdot 2 \\
36 \cdot 5\end{array}$ & \begin{tabular}{l} 
Nil \\
DSCG; OR \\
DSCG; OR \\
DSCG; OR \\
DSCG; OR; PR \\
DSCG \\
\multicolumn{1}{c}{ OR } \\
DSCG; OR \\
DSCG; OR
\end{tabular} & $\begin{array}{c}2 \\
\text { Unknown } \\
5 \\
\text { Unknown } \\
3 \\
6 \\
1 \\
2 \\
5 \\
3\end{array}$ \\
\hline
\end{tabular}

$\star \mathrm{OR}=$ orciprenaline $; \mathrm{DSCG}=$ disodium cromoglycate $; \mathrm{PR}=$ promethazine hydrochloride.

exercise at $1,3,5,10$, and 15 minutes and beyond this time until spontaneous improvement had begun to occur.

Predicted normal values for the calculation of initial PEFR (\%) were taken from Godfrey, Kamburoff, and Nairn (1970). The following indices were calculated:

(i) Fall in PEFR (\%) =

$$
\frac{\text { Initial PEFR }- \text { minimum PEFR }}{\text { Initial PEFR }} \times 100
$$

(ii) Rise in PEFR (\%) =

Maximum PEFR during exercise-Initial PEFR Initial PEFR $\times 100$

In $95 \%$ of normal schoolchildren, PEFR falls by no more than $12.5 \%$ after treadmill exercise and the rise in PEFR during exercise is less than 19\% (personal observations). The change in PEFR has been related to the initial PEFR rather than to a predicted value since the scatter of normal values is so great.

Paired sample ' $t$ ' tests have been used throughout to assess the significance of differences between tests. Differences are said to be significant when $P<0.05$.

Sequence of studies. An initial test was performed without prior drug administration. This test served as a control test. The order in which the other tests in the series were performed was randomized. These tests included the administration of a capsule of DSCG (disodium cromoglycate $10 \mathrm{mg}$ + lactose $10 \mathrm{mg}$ ) 20 minutes before exercise, immediately before exercise, or immediately after exercise. In a further test, 7 of the children were given a capsule 20 minutes before exercise, which was identical in taste and appearance to the DSCG capsule, but which contained lactose $15 \mathrm{mg}+$ sodium sulphate $5 \mathrm{mg}$. This was called the placebo test.

\section{Results}

There was no significant difference between values for PEFR between the tests, though the mean PEFR was lower before the test in which DSCG was given at the start of exercise than before the other tests (Table II).
The fall in PEFR after exercise was greatest in the control test and there was no significant difference between the results of those patients who performed treadmill tests and those patients who performed the corridor exercise tests (grouped ' $t$ ' test). The results of the control and placebo tests were not significantly different (Table II). The fall in PEFR was least in the 2 tests in which DSCG was given 20 minutes before exercise or at the start of exercise, and was significantly less than in the control and placebo tests $(P<0.001)$. There was no significant difference between the results of the 2 tests in which DSCG was given before exercise.

The result of the test in which DSCG was given at the end of exercise was significantly different from the results of all the other tests. Fall in PEFR was significantly less than that occurring in the control test $(P<0.05)$ and significantly greater than that occurring in the two tests in which DSCG was given before exercise $(P<0.01)$.

The rise in PEFR during exercise was greatest when patients had been given DSCG at the start of exercise (Table II). There was a significant difference in rise in PEFR between this test and the control and placebo tests. In this test, preexercise PEFR was measured before inhalation of DSCG.

A characteristic series of results, those of Case 8, are shown in Fig. 1. Mean values of rise and fall in PEFR (\%) are illustrated in Fig. 2.

\section{Discussion}

The characteristic response of asthmatic children to exercise is biphasic: while bronchodilatation (recognized by a rise in PEFR) occurs during the early minutes of exercise, exercise is followed by bronchoconstriction (fall in PEFR below pre- 
TABLE II

Results of Exercise Tests

\begin{tabular}{|c|c|c|c|c|c|c|c|c|c|c|c|c|c|c|c|c|}
\hline \multirow{2}{*}{$\begin{array}{l}\text { Case } \\
\text { No. }\end{array}$} & \multirow{2}{*}{$\begin{array}{c}\text { Type } \\
\text { of } \\
\text { Exercise^ }\end{array}$} & \multicolumn{3}{|c|}{ No Drugt } & \multicolumn{3}{|c|}{ Placebot } & \multicolumn{3}{|c|}{$\begin{array}{c}\text { DSCG } 20 \text { Minutes } \\
\text { Before Exerciset }\end{array}$} & \multicolumn{3}{|c|}{$\begin{array}{c}\text { DSCG at Start } \\
\text { of Exerciset }\end{array}$} & \multicolumn{3}{|c|}{$\begin{array}{l}\text { DSCG at End } \\
\text { of Exerciset }\end{array}$} \\
\hline & & $\begin{array}{l}\text { Rest } \\
(\%)\end{array}$ & $\begin{array}{l}\text { Rise } \\
(\%)\end{array}$ & $\begin{array}{l}\text { Fall } \\
(\%)\end{array}$ & $\begin{array}{l}\text { Rest } \\
(\%)\end{array}$ & $\begin{array}{l}\text { Rise } \\
(\%)\end{array}$ & $\begin{array}{l}\text { Fall } \\
(\%)\end{array}$ & $\begin{array}{l}\text { Rest } \\
(\%)\end{array}$ & $\begin{array}{l}\text { Rise } \\
(\%)\end{array}$ & $\begin{array}{l}\text { Fall } \\
(\%)\end{array}$ & $\begin{array}{l}\text { Rest } \\
(\%)\end{array}$ & $\begin{array}{l}\text { Rise } \\
(\%)\end{array}$ & $\begin{array}{l}\text { Fall } \\
(\%)\end{array}$ & $\begin{array}{l}\text { Rest } \\
(\%)\end{array}$ & $\begin{array}{l}\text { Rise } \\
(\%)\end{array}$ & $\begin{array}{l}\text { Fall } \\
(\%)\end{array}$ \\
\hline $\begin{array}{c}1 \\
2 \\
3 \\
4 \\
5 \\
6 \\
7 \\
8 \\
9 \\
10 \\
\text { Mean } \\
\text { SEM } \ddagger\end{array}$ & $\begin{array}{l}T \\
C \\
T \\
T \\
C \\
T \\
C \\
T \\
C \\
T\end{array}$ & $\begin{array}{r}81 \\
66 \\
117 \\
70 \\
132 \\
85 \\
89 \\
108 \\
100 \\
115 \\
96 \cdot 3 \\
6 \cdot 9\end{array}$ & $\begin{array}{c}18 \\
32 \\
0 \\
15 \\
0 \\
8 \\
18 \\
12 \\
4 \\
0 \\
10 \cdot 7 \\
3 \cdot 2\end{array}$ & $\begin{array}{l}40 \\
20 \cdot 5 \\
26 \\
51 \\
21 \\
75 \\
80 \\
63 \\
70 \\
38 \\
48 \cdot 5 \\
7 \cdot 2\end{array}$ & $\begin{array}{r}88 \\
110 \\
92 \\
125 \\
99 \\
- \\
\overline{1} \\
104 \\
100 \\
103 \cdot 0 \\
4 \cdot 6\end{array}$ & $\begin{array}{l}10 \\
2 \\
11 \\
0 \\
12 \\
- \\
- \\
6 \\
0 \\
5 \cdot 9 \\
2 \cdot 0\end{array}$ & $\begin{array}{l}56 \\
18 \\
52 \\
29 \\
60 \\
- \\
- \\
25 \\
37 \\
39 \cdot 7 \\
6 \cdot 2\end{array}$ & $\begin{array}{r}94 \\
91 \\
116 \\
71 \\
142 \\
62 \\
92 \\
108 \\
103 \\
111 \\
99 \cdot 0 \\
7 \cdot 2\end{array}$ & $\begin{array}{r}0 \\
18 \\
0 \\
25 \\
0 \\
32 \\
18 \\
8 \\
14 \\
3 \\
11 \cdot 8 \\
3 \cdot 6\end{array}$ & $\begin{array}{l}21 \\
0 \\
14 \\
1 \cdot 5 \\
8 \\
24 \\
31 \\
0 \\
0 \\
27 \\
12 \cdot 7 \\
3 \cdot 9\end{array}$ & $\begin{array}{c}79 \\
69 \\
90 \\
78 \\
94 \\
80 \\
70 \\
92 \\
94 \\
115 \\
86 \cdot 1 \\
4 \cdot 4\end{array}$ & $\begin{array}{c}2 \\
49 \\
13 \\
25 \\
6 \\
7 \cdot 5 \\
48 \\
27 \\
10 \\
2 \cdot 5 \\
19 \\
5 \cdot 6\end{array}$ & $\begin{array}{r}11 \\
0 \\
13 \\
13 \\
6 \\
36 \\
14 \\
11 \\
6 \\
26 \\
12 \cdot 4 \\
3 \cdot 5\end{array}$ & $\begin{array}{c}77 \cdot 5 \\
85 \\
91 \\
72 \\
144 \\
67 \\
73 \\
118 \\
82 \\
124 \\
93 \cdot 4 \\
8 \cdot 3\end{array}$ & $\begin{array}{c}13 \\
17 \\
10 \\
24 \\
4 \\
32 \\
18 \\
0 \\
15 \\
0 \\
13 \cdot 3 \\
3 \cdot 2\end{array}$ & $\begin{array}{l}42 \\
13 \\
21 \\
36 \cdot 5 \\
12 \\
45 \\
43 \\
56 \\
52 \\
37 \\
35 \cdot 8 \\
4 \cdot 9\end{array}$ \\
\hline
\end{tabular}

$\star^{\mathrm{T}}=$ treadmill exercise; $\mathrm{C}=$ corridor exercise.

†Rest $\%=$ pre-exercise value of PEFR expressed as a percentage of predicted normal value.

Rise $\%=$ rise in PEFR during exercise, as a percentage of pre-exercise value.

Fall $\%=$ fall in PEFR after exercise, as percentage of pre-exercise value.

$\ddagger$ SEM $=$ standard error of mean.

exercise levels) if prolonged beyond about 2 minutes (Connolly and Godfrey, 1970). Bronchoconstriction often starts during exercise (Fig. 1).

The bronchodilator effect of early exercise caused the PEFR to rise to approximately the same absolute level in each of the tests (the sum of the mean pre-exercise value of PEFR $\%+$ mean rise in PEFR \% was similar in all tests). This bronchodilatation appeared to be enhanced in the test in which exercise was immediately preceded by administration of DSCG, but only because the

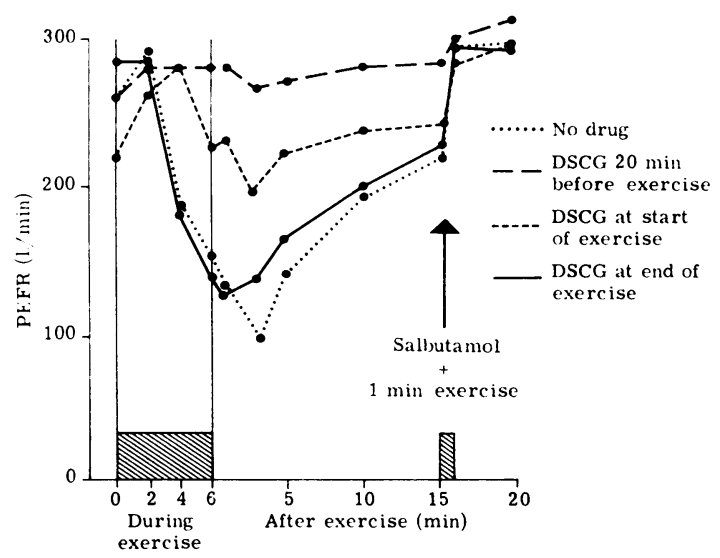

FIG. 1.-Changes in PEFR throughout the series of tests in Case 8. initial mean PEFR was slightly lower in this test than before the other tests. When given 20 minutes before exercise, DSCG certainly caused no enhancement of bronchodilatation in early exercise, whether assessed by the rise in PEFR \% or by the highest absolute level of PEFR achievement during exercise.

There was no significant overall placebo effect. This confirms previous personal observations on a group of asthmatic children with EIB.

The rate of action of DSCG is such that when it

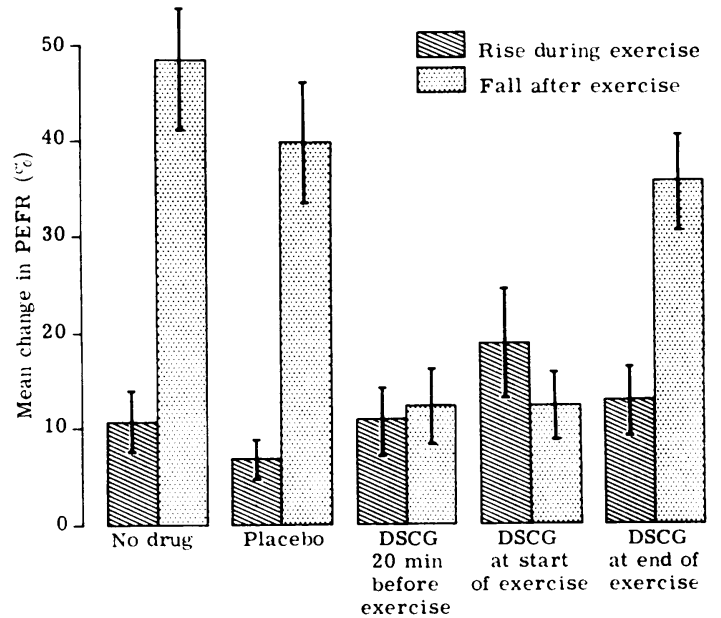

FIG. 2.-Mean values of rise (\%) and fall (\%) in PEFR for all tests $( \pm 1 S E)$. 
was administered immediately before a 6-minute exercise test, it protected against EIB as effectively as when it was administered 20 minutes before exercise.

This result may be contrasted with the single case report of Blackhall and Jones (1970) in which DSCG administered 30 minutes before exercise was more effective in preventing EIB than DSCG given 15 minutes before exercise. In their patient, DSCG did not seem to have any beneficial effect when given 1 hour or more before exercise. In studies of asthmatic children (personal observations), we have shown DSCG to have some effect when taken up to 5 to 6 hours before exercise. The reason for this difference is not apparent but may reflect individual differences in responsiveness to the drug.

Since in most children bronchoconstriction starts after 2 to 4 minutes of exercise (e.g. Fig. 1), the drug must be taking maximum effect within 2 to 4 minutes of inhalation. There was no difference in response to DSCG between those patients whose PEFR began to fall during exercise and those in whom this only occurred after exercise. DSCG inhaled at the end of exercise (i.e. immediately after exercise stopped) had a small but significant ameliorating effect on bronchoconstriction. This implies that the fall in PEFR is not solely in response to a 'trigger' pulled during exercise. It suggests that a mechanism which can produce bronchoconstriction is in operation during the phase after exercise and that this mechanism is susceptible almost immediately to the effects of DSCG. An alternative, that DSCG might diminish bronchoconstriction by acting as a bronchodilator, is unlikely since no immediate bronchodilator effect has been reported for DSCG and bronchodilation during exercise was not augmented in the present study by DSCG.

We are grateful to Fisons Pharmaceuticals Ltd. for financial support.

\section{REFERENCES}

Blackhall, M. I., and Jones, R. S. (1970). Effect of Intal on postexercise broncho-constriction in asthma. In Disodium Cromoglycate in Allergic Airways Disease, p. 63. Ed. by J. Pepys and A. W. Frankland. Butterworths, London.

Connolly, N. M. C., and Godfrey, S. (1970). Assessment of the child with asthma. Fournal of Asthma Research, 8, 31 .

Davies, S. E. (1968). Effect of disodium cromoglycate on exerciseinduced asthma. British Medical Fournal, 3, 593.

Godfrey, S., Kamburoff, P. L., and Nairn, J. R. (1970). Spirometry, lung volumes and airway resistance in normal children aged 5-18 years. British fournal of Diseases of the Chest, 64, 15.

Jones, R. S., Buston, M. H., and Wharton, M. J. (1962). The effect of exercise on ventilatory function in the child with asthma. British Fournal of Diseases of the Chest, 56, 78.

Pepys, J., Hargreave F. E., Chan, M., and McCarthy, D. S. (1968). Inhibitory effects of disodium cromoglycate on allergeninhalation tests. Lancet, 2, 134.

Scadding, J. G. (1969). Management of asthma. British Medical fournal, 3, 165.

Correspondence to Dr. M. Silverman, Institute of Diseases of the Chest, Fulham Road, London. 